do tradicionalmente como obra de Velázquez, pero adjudicado en la actualidad sin reservas al propio Mazo ${ }^{14}$. Consiguientemente la mujer sentada sería Ana de la Vega con su hija, la última del pintor nacida del tercer matrimonio. No cabe duda de que el retrato familiar de Mazo es un homenaje a los modos pictóricos y conceptuales de su suegro Diego Velázquez y desde el punto de vista de los personajes representados una síntesis de las familias que formó el pintor, pues aparecen los hijos de sus tres matrimonios, compendiadas en los últimos años de su vida.

Respecto a la pintura que nos ocupa, por el momento no es posible reconstruir su historia anterior a su adquisición en Francia en una subasta pública. Parece lógico pensar que a la muerte de Martínez del Mazo quedara entre los bienes y utensilios del taller. Pero por el momento no se conoce la existencia de ningún testamento ni inventario de los bienes del pintor en el que se pueda rastrear la presencia de éste retrato y de otros del mismo tipo que parece que el pintor realizó a sus hijos como estudios previos para el gran cuadro de Viena, como lo demuestra el lienzo de la Dulwich Picture Gallery.

Dr. ISMAel GutiérRez PASTOR Universidad Autónoma de Madrid

\title{
NUEVAS ESCULTURAS DE LUIS Y JOSÉ SALVADOR CARMONA ?*
}

En la villa ducal de Béjar es, especialmente, venerada una imagen de la Piedad que, procedente del desaparecido monasterio franciscano, recibe hoy culto en la iglesia de Santa María la Mayor (figs. 1 y 2). La imagen procesiona durante la Semana Santa y allí se la tiene, en general, como obra del escultor salmantino Alejandro Carnicero.

La escultura, muy hermosa, no encaja con lo conocido de Carnicero. Precisamente este escultor tallaba el mismo tema para la hornacina superior del retablo de la catedral de Coria, en Cáceres, terminado en 1748 , y su estilo, más dramático y con un tratamiento de paños más minucioso y movido, es distinto al de la obra que nos ocupa ${ }^{1}$. En la Piedad de Béjar, lo que llama especialmente la atención es su serenidad y su sencilla composición. La expresión de María es de un dramatismo muy contenido, el rictus de dolor no descompone la dulzura del rostro, y su pena aparece, solo visible, en la tristeza de la mirada.

La figura de Cristo descansa, blandamente recostada, sobre la pierna derecha doblada de María, al tiempo que extiende la izquierda para crear un hueco acogedor. Con una de las manos se ayuda para sostener la espalda y la cabeza, mientras que con la otra sostiene uno de los brazos. Cristo deja caer inerte el brazo derecho que llega a tocar el suelo y extiende ambas piernas formando, sin estridencias, un grupo piramidal. Su cuerpo, de suave anatomía, se cubre sumariamente con un paño de pureza, y muestra muy visible la sangre del costado. La cabeza, caída hacia un lado y ya sin corona, muestra barba y larga cabellera que se derrama por el costado derecho. Hilillos de sangre cruzan el rostro y muestra huellas de una herida muy significativa, la de una espina que ha entrado por encima de una de las cejas y ha salido sobre el párpado cerrado. La efigie presenta una novedad extremadamente curiosa, en el interior de

${ }^{14}$ Véase la obra de Javier Portús. Guía Velázquez. Museo del Prado. Madrid, 1999, pp. 188-189.

* Quiero expresar mi agradecimiento a Juan Félix Sánchez Sancho, joven investigador de la villa de Béjar, por su entusiasta colaboración para llevar a cabo este trabajo.

${ }^{1}$ Andrés Ordax, Salvador, «El escultor Alejandro Carnicero: su obra en Extremadura», Norba, 1980, pp. 9-25. Martín González, J.J., Escultura Barroca en España (1600 - 1770), Ed. Cátedra, Madrid, 1983. 
la herida del costado, invisible a la vista, hay una pequeña cerradura que abre parte del pecho, transformándose en sagrario.

María viste de modo tradicional, túnica roja, velo blanco, que cae en suaves pliegues por ambos lados de la cara, y amplio manto azul. Tras ella se alza la cruz, de tronco nudoso, «vestida» con la sábana de la descensión.

La escultura recuerda el estilo de Luis Salvador Carmona que repitió, al menos, tres veces el tema, aunque esta Piedad es más contenida y se sienten más, ante ella, los aires del neoclasicismo. De las versiones de Carmona, una en Salamanca, otra en León y otra en Madrid, la imagen de Béjar recuerda a las tres. De la de Madrid y León copia la colocación de Cristo y el modo de sostener el brazo. Pero es, sin duda, con la de Salamanca con la que más relación guarda en la postura del Cristo inclinado hacia el mismo lado e idéntica caída del brazo derecho inerte. Otros elementos que las tres de Carmona tienen es la posición del manto y velo sobre la cabeza de la Virgen, terminado en pico, lo que deja despejada la frente, y ese pliegue, como en ese, que forma la túnica en el escote. La de Béjar mantiene, aunque poco marcada, la ese del cuello, pero el manto cae sobre la frente, sombreándola intensamente.

Tras el estudio de estas y otras diferencias creemos poder apuntar no a Luis Salvador Carmona, sino a su sobrino José, que con él aprendió el oficio y se limitó a copiar, a veces de modo servil, al tío, repitiendo los tipos pero sin su fuerza y su gracia. Sin embargo, conforme su obra va saliendo a la luz, vemos en algunas de sus esculturas aciertos que la hacen digna de búsqueda y estudio, como ocurre con la imagen de la Virgen del Rosario de Ezcaray ${ }^{2}$, la Divina Pastora y el San Francisco de Asís de Arenas de San Pedro ${ }^{3}$ o el San Pedro de Alcántara de Priego, en Cuenca ${ }^{4}$, a la que ahora habrá que añadir esta interesantísima de Béjar.

Por último queremos señalar que esta Piedad, debido a su azarosa historia, se encuentra un tanto deteriorada, de manera especial en su policromía, habiendo recibido más de un repinte que convendría subsanar.

Los datos que en la villa de Béjar se tienen de la imagen la vinculan con una mujer, especialmente devota, llamada María Peña García, conocida popularmente como «La Morala», que, según la tradición local, tuvo una visión de la Piedad que quiso se perpetuase en la imagen, que se colocó en el monasterio franciscano donde, debido al sagrario que la escultura lleva en el pecho, hacía de monumento del Jueves Santo ${ }^{5}$. Para fecharla, aunque no podamos tomar el dato como definitivo, se cuenta con una cifra tope que es la de 1760, en que muere la sierva de Dios, y correspondería a los últimos años de la actividad de Luis Salvador Carmona, cuando la colaboración de los discípulos debió ser mayor y cuando su sobrino, aun joven, trabajaría muy cercano al tío y éste podía estar especialmente pendiente de su actividad.

Al desaparecer el monasterio franciscano con la desamortización, la imagen fue llevada a la iglesia donde hoy se guarda ${ }^{6}$. El que la escultura se tallase para un convento franciscano aumenta las posibilidades de la intervención de José Salvador Carmona ya que, como vamos demostrando, trabajó mucho para conventos de la orden como el de San Pedro de Alcántara, en Arenas de San Pedro, el de Ntra. Sra. del Rosario, cercano a Oropesa ${ }^{7}$, el de la Victoria de

\footnotetext{
${ }^{2}$ Martín González, J.J., Luis Salvador Carmona. Escultor y Académico, Ed. Alpuerto, Madrid,1990.

${ }^{3}$ Nicolau Castro, J., «En torno a Luis Salvador Carmona y la escultura de su tiempo», BSAA, T. LVI, 1990, pp. 562-568

${ }^{4}$ Nicolau Castro, J., «Las esculturas de José Salvador Carmona del convento de San Miguel de las Victorias de Priego» (Cuenca), BSAA, T.LIX, 1993, pp. 455-464.

${ }_{5}^{5}$ Muñoz García, J., «La sierva de Dios, María de Jesús García, terciaria franciscana», Bejar en Madrid, № 1463, abril de 1950. López Álvarez, A. «Huesos y olores santos en el Béjar del siglo xvil», Centro de Estudios Bejaranos, 1998.

${ }^{6}$ Entre los inventarios de la iglesia de Sta. María, aparece situada por primera vez allí la imagen en el del año 1893. En ese año estaba colocada, de manera provisional, en la parte baja del retablo mayor.

${ }^{7}$ Nicolau Castro, J., «Nuevas obras de Luis y José Salvador Carmona», Archivo Español de Arte, № 300, 2002, pp. 407 414.
}

AEA, LXXVIII, 2005, 311, pp. 297 a 331 

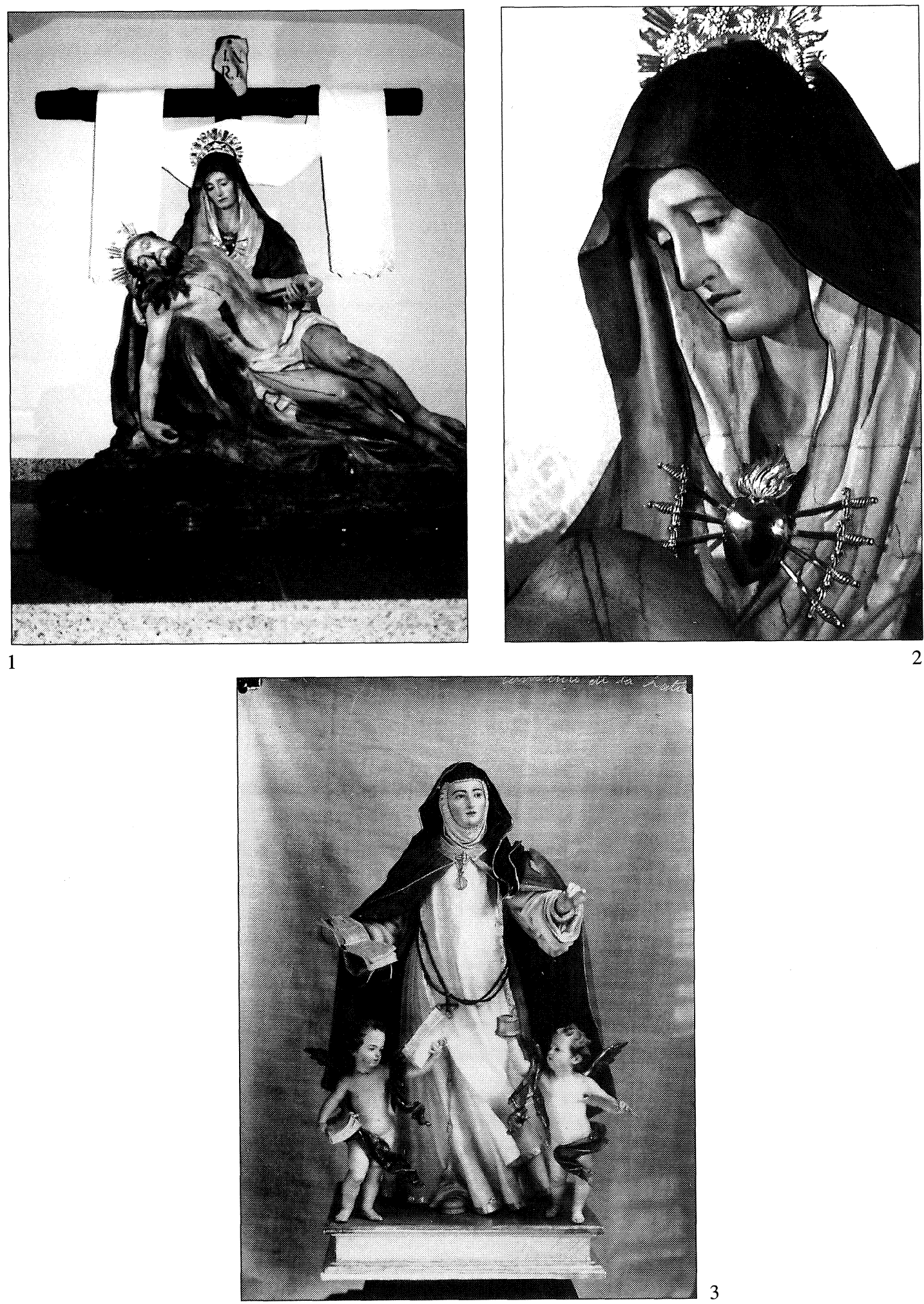

Fig. 1. José Salvador Carmona (?). Piedad. Iglesia de Sta. M. ${ }^{a}$ la Mayor. Béjar (Salamanca)

Fig. 2. José Salvador Carmona (?). Piedad (detalle). Iglesia de Sta. María la Mayor. Béjar (Salamanca).

Fig. 3. Luis Salvador Carmona. Venerable sor María de Ágreda. Concepcionistas de La Latina. Madrid. 
Priego, en Cuenca, y alguno más. En la actividad artística de estos conventos es posible no estuviese ajeno el famoso obispo franciscano Eleta, confesor del rey Carlos III.

Otra obra que, con seguridad, podemos asignar a Luis Salvador Carmona es la espléndida escultura de sor María Jesús de Ágreda que guardan en Madrid las Religiosas Concepcionistas de La Latina (fig. 3), que ha podido ser contemplada en la magna exposición celebrada sobre la Venerable en su convento de la villa soriana ${ }^{8}$.

Pero no parece haberse hecho referencia al dato de que la escultura fue mutilada durante la pasada guerra civil, desapareciendo entonces dos deliciosos angelillos, que se disponían a uno y otro lado de la peana, y que daban a la composición un aspecto muy diferente al actual. Felizmente, en la fototeca del Instituto de Historia del CSIC, hemos localizado una antigua fotografía por la que podemos saber como era el grupo original.

La Venerable se nos muestra vestida con el hábito blanco de las religiosas concepcionistas, ceñido con el cinturón franciscano que llegaba hasta los pies en la versión antigua, manto azul, con el escudo de la orden situado en el lado derecho, y toca blanca cubierta, en parte, por el velo negro. Del cuello pendía una medalla de la Inmaculada que hoy ha perdido. Sus facciones son las repetidas una y otra vez por Carmona, cejas muy marcadas y rectas, ojos especialmente vivos, nariz larga y boca pequeña y un óvalo de la cara muy redondeado y lleno, enmarcado en este caso por la toca fruncida. Los brazos los muestra abiertos y en las manos porta una pluma y un libro, haciendo referencia a su faceta de escritora. Las ropas del hábito se mueven hacia un lado, como si la figura hiciera ademán de avanzar hacia adelante, viéndose bajo el hábito el pie adelantado calzado con sandalia. Recuerda a la Santa Teresa de la parroquia de Santa Marina de Vergara, en Guipúzcoa ${ }^{9}$, que hace también ademán de lanzarse a andar. Pero parte de este movimiento quedaba atemperado en la versión original por los dọ deliciosos angelillos, inconfundiblemente carmonescos, que la Venerable tenía a un lado y otro, portando uno de ellos una pluma y un tintero y el otro dos libros. Estos cubrían levemente su desnudez con unos paños que, a modo de filacterias, revoloteaban en torno a sus cuerpecillos. Eran en todo semejantes a los ángeles que acompañan al San Mateo de la Granja de San Ildefonso o al San Dámaso, en obra venerada en Madrid y conocida hoy solamente por grabado.

Opinamos que esta figura de la Venerable sor María Jesús de Ágreda es una de las mejores y más recias figuras femeninas salidas de las gubias del escultor vallisoletano.

Finalmente, aunque con mayores vacilaciones, queremos llamar la atención sobre una hermosa Virgen de los Dolores o Soledad que se venera en la parroquia de San Juan del Mercado de la villa de Atienza, en Guadalajara, y que es la patrona de la localidad. Es imagen de bastidor, de las que Carmona repitió más de una vez, de mediados el siglo xvIII, y muestra una talla especialmente cuidada y bella. Se da la circunstancia de que para Atienza trabajaron Luis Salvador Carmona y su sobrino José, lo que puede ser un dato más para tener en cuenta esta atribución ${ }^{10}$.

\footnotetext{
${ }^{8}$ Fernández Gracia, R., Arte, Devoción y Política. La promoción de las artes en torno a sor María de Ágreda, Exma. Diputación de Soria, 2002 y «En torno a la exposición sor María de Ágreda. El poder de la palabra y la imagen», Revista de Soria, $\mathrm{N}^{\circ}$ 36, 2002, e Iconografía de la Venerable Sor María de Ágreda, Caja Duero, 2003.

9 García Gainza, M.C., «Dos grandes conjuntos del Barroco en Guipúzcoa. Nuevas obras de Luis Salvador Carmona», Revista de la Universidad Complutense, Vol. XXII, 1973, pp. 81-110 y El Escultor Luis Salvador Carmona, Publicaciones de la Universidad de Navarra, 1990.

${ }^{10}$ Quesada, J.M. y Jiménez, A., El Arte en Atienza, Guadalajara, 1996.
}

AEA, LXXVIII, 2005, 311, pp. 297 a 331 